\title{
Exaggerated Response of a Vasopressin-Enhanced Green Fluorescent Protein Transgene to Nociceptive Stimulation in the Rat
}

\author{
Hitoshi Suzuki, ${ }^{1,2}$ Makoto Kawasaki, ${ }^{1,2}$ Hideo Ohnishi, ${ }^{2}$ Hiroki Otsubo, ${ }^{1}$ Toyoaki Ohbuchi, ${ }^{1}$ Akiko Katoh, ${ }^{1}$ \\ Hirofumi Hashimoto, ${ }^{1}$ Toru Yokoyama, ${ }^{1}$ Hiroaki Fujihara, ${ }^{1}$ Govindan Dayanithi, ${ }^{3}$ David Murphy, ${ }^{4}$ \\ Toshitaka Nakamura, ${ }^{2}$ and Yoichi Ueta ${ }^{1}$ \\ Departments of ${ }^{1}$ Physiology and ${ }^{2}$ Orthopaedics, School of Medicine, University of Occupational and Environmental Health, Kitakyushu 807-8555, Japan, \\ ${ }^{3}$ Department of Cellular Neurophysiology, Institute of Experimental Medicine, European Union Research Centre of Excellence, CZ-14220 Prague, Czech \\ Republic, and ${ }^{4}$ Molecular Neuroendocrinology Research Group, The Henry Wellcome Laboratories for Integrative Neuroscience and Endocrinology, \\ University of Bristol, Bristol BS1 3NY, United Kingdom
}

Nociceptive stimulation elicits neuroendocrine responses such as arginine vasopressin (AVP) release as well as activation of the hypothalamo-pituitary-adrenal axis. We have generated novel transgenic rats expressing an AVP-enhanced green fluorescent protein (eGFP) fusion gene, and we examined the effects of nociceptive stimulation on transgene expression in the hypothalamus after subcutaneous injection of saline or formalin into the bilateral hindpaws in these rats. We have assessed (1) AVP levels in plasma and the changes of eGFP mRNA and AVP heteronuclear RNA (hnRNA) in the supraoptic nucleus (SON) and the paraventricular nucleus (PVN) using in situ hybridization histochemistry, (2) gene expression changes in distinct magnocellular and parvocellular divisions of the PVN, (3) eGFP fluorescence in the SON, the PVN, the median eminence (ME), and the posterior pituitary gland (PP). Plasma AVP levels were significantly increased 15 min after formalin injection. In the same time period, the AVP hnRNA levels in the PVN were increased, especially in the parvocellular division of the PVN in formalin-injected rats. In the same region, eGFP mRNA levels after formalin injection were also significantly increased to a much greater extent than those of AVP hnRNA. The eGFP fluorescence in the SON, the PVN, the ME, and the $\mathrm{PP}$ was markedly increased in formalin-injected rats and especially increased in the parvocellular divisions of the PVN. Together, our results demonstrate robust and rapid changes in the expression of the AVP-eGFP transgene in the rat hypothalamus after acute nociceptive stimulation.

\section{Introduction}

Nociceptive stimulation elicits a plethora of neuroendocrine responses including arginine vasopressin (AVP) release (Kendler et al., 1978; Onaka et al., 1986, 1996; Onaka and Yagi, 1988) and activation of the hypothalamo-pituitary-adrenal (HPA) axis (Aloisi et al., 1995, 1996; Pacák et al., 1995; Culman et al., 1997; Persoons et al., 1997; Taylor et al., 1998). The formalin test for nociception is commonly used in rats and mice to assess the response of an animal to moderate, continuous pain (Abbott et al., 1982a), and this model is thought to resemble clinical pain

\footnotetext{
Received June 5, 2009; revised Aug. 19, 2009; accepted Sept. 6, 2009.

This work was supported in part by the Ministry of Education, Culture, Sports, Science and Technology (Japan) Grant-in-Aid for Scientific Research (C) 19591771 (H.0.), Grant-in-Aid for Scientific Research (A) 18209026 (Y.T.), and Grant-in-Aid for Scientific Research on Priority Areas 18077006 (Y.U.). D.M. is supported by the Biotechnology and Biological Sciences Research Council and the Medical Research Council (United Kingdom). We thank Yoshimi Asao and Kumiko Nasu for their technical assistance and James Dutt for critical reading and language editing of this manuscript.

Correspondence should be addressed to Dr. Yoichi Ueta, Department of Physiology, School of Medicine, University of Occupational and Environmental Health, 1-1 Iseigaoka, Yahatanishi-ku, Kitakyushu 807-8555, Japan. E-mail: yoichi@med.uoeh-u.ac.jp.

DOI:10.1523/JNEUROSCI.2624-09.2009

Copyright $\odot 2009$ Society for Neuroscience $\quad$ 0270-6474/09/2913182-08\$15.00/0
}

(Dubuisson and Dennis, 1977; Dennis and Melzack, 1980; Abbott et al., 1982a,b).

AVP-containing neurons in the magnocellular division of the paraventricular nucleus (PVN) and in the supraoptic nucleus (SON) project their axons through the internal layer of the median eminence (ME), to terminations in the posterior pituitary gland (PP), from where AVP is secreted into the systemic circulation (Vandesande and Dierickx, 1975). However, AVP- and corticotropin-releasing hormone (CRH)-containing neurons in the parvocellular division of the PVN project their axons into the external layer of the ME, from where the neurohormones are secreted into the pituitary portal circulation (Harbuz and Lightman, 1992; Antoni, 1993).

Previous studies demonstrated that the plasma concentration of AVP is increased after subcutaneous injection of formalin into the bilateral hindpaws (Kurose et al., 2001). Moreover, expression of AVP heteronuclear RNA (hnRNA) was increased in the hypothalamic PVN after subcutaneous injection of formalin (Kurose et al., 2001). However, the role of upregulated AVP after the formalin test has not been determined.

We have generated novel transgenic rat line expressing AVPenhanced green fluorescent protein (eGFP) fusion gene (Ueta et 

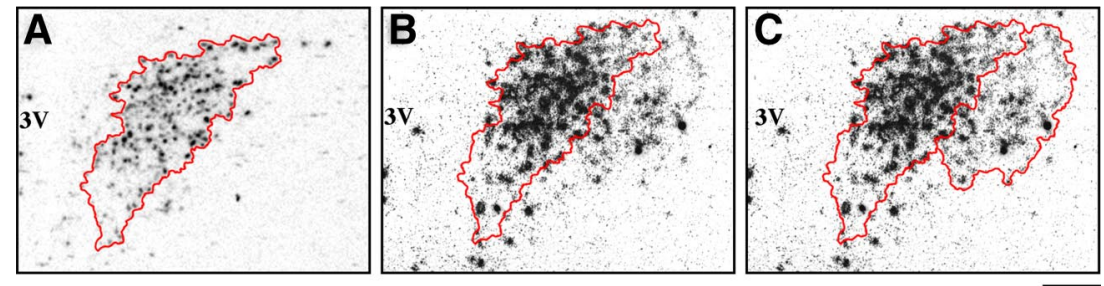

Figure 1. Quantitative analysis of AVP hnRNA, c-fos mRNA, and eGFP mRNA in the parvocellular ( $\boldsymbol{B}$ ) and magnocellular ( $\boldsymbol{C}$ divisions of the paraventricular nucleus. In situ hybridization histochemistry was performed and the contour of the corticotropinreleasing hormone mRNA positive area $(\boldsymbol{A})$ was overlaid on the digitized image of AVP hnRNA, c-fos mRNA, and eGFP mRNA obtained from the adjacent section. Scale bar, $100 \mu \mathrm{m}$. 3V, Third ventricle.
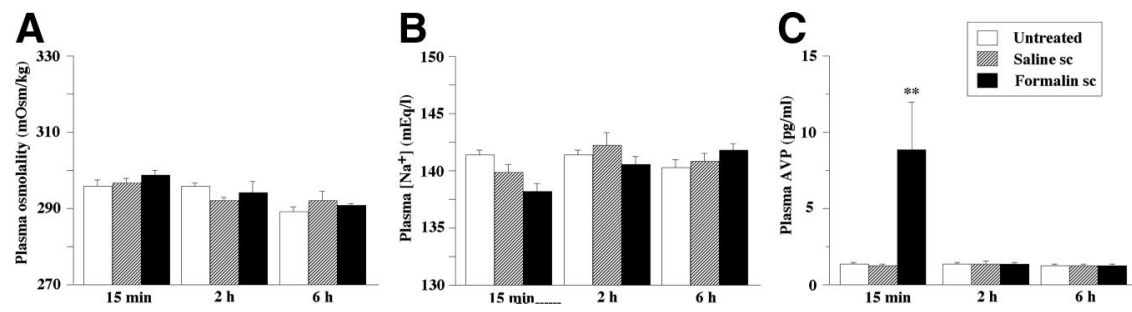

Figure 2. Changes in plasma osmolality $(\boldsymbol{A})$, plasma $\left[\mathrm{Na}^{+}\right](\boldsymbol{B})$, and plasma AVP $(\boldsymbol{C})$ in untreated rats, saline subcutaneously injected rats, and formalin subcutaneously injected rats. Points, Mean $(n=6)$; error bars, SEM. ${ }^{* *} p<0.01$ compared with each control.

al., 2005). Expression of the transgene is characterized by robust fluorescence in the PVN, the SON, the ME, and the PP, in close parallel with the biosynthesis, transport, and storage of endogenous AVP gene products (Ueta et al., 2005). In the present study, using AVP-eGFP transgenic rats, we analyzed the response of the PVN to acute nociceptive stress activation of the HPA axis using formalin test model. First, we measured changes in osmolality, sodium, and AVP in plasma over a time course after formalin or saline administration. Second, over the same time period, we examined changes in AVP hnRNA, c-fos mRNA, CRH mRNA, and eGFP mRNA in the SON and functionally distinct regions of the PVN. Finally, we examined eGFP fluorescence in the SON, the $\mathrm{PVN}$, the ME, and the PP after formalin or saline injection. We propose that this novel AVP-eGFP transgenic rat is useful to study the changes in the AVP gene expression in the hypothalamus under acute nociceptive stress.

\section{Materials and Methods}

Animals. Adult male AVP-eGFP Wistar transgenic rats, weighing 290$430 \mathrm{~g}$, were bred and maintained as described previously (Ueta et al., 2005). Three rats per cage were housed at room temperature $\left(22-25^{\circ} \mathrm{C}\right)$ with a 12 h light (7:00 A.M. to 7:00 P.M.)/dark (7:00 P.M. to 7:00 A.M.) cycle with access to food and water available ad libitum. All experiments were performed in strict accordance with guidelines on the use and care of laboratory animals as set out by the Physiological Society of Japan and approved by the Ethics Committee of Animal Care and Experimentation of University of Occupational and Environmental Health, Japan. All rats were screened by PCR analysis of genomic DNA extracted from rat tail biopsies (Ueta et al., 2005). Unless otherwise specified, all standard chemicals used in this study were purchased from Sigma-Aldrich.

Experimental procedure. The AVP-eGFP transgenic rats were divided into three groups ( $n=18$ in each group). In group 1 (untreated), rats were handled equally to the other groups and no treatment was given. In group 2 (saline-injected), rats were bilaterally subcutaneously injected with $100 \mu \mathrm{l}$ of $0.9 \%$ saline into the dorsal surface of each hindpaw using a sterile syringe with a 27 gauge needle. In group 3 (formalin-injected), rats were injected with $100 \mu \mathrm{l}$ of $5 \%$ formalin in saline into the dorsal surface of each hindpaw using a sterile syringe with 27 gauge needle. Care was taken while handling the animals for these experiments. Animals from each group were decapitated $15 \mathrm{~min}, 2 \mathrm{~h}$, and $6 \mathrm{~h}$ after subcutaneous injection of formalin or saline during 9:00 A.M. to 10:00 A.M. The rats without treatment were also decapitated at the same time intervals. To measure the plasma osmolality, sodium, and AVP, trunk blood was collected in plastic tubes containing $100 \mu \mathrm{l}$ of heparin (200 $\mathrm{U} / \mathrm{ml}$; Sigma-Aldrich) and centrifuged at $1700 \times g$ at $4^{\circ} \mathrm{C}$ for $10 \mathrm{~min}$ for measurement of the plasma osmolality, sodium, and AVP. The brains were rapidly removed and placed onto a glass plate on dry ice and stored at $-80^{\circ} \mathrm{C}$ until used for in situ hybridization histochemistry to detect AVP hnRNA, $c$-fos mRNA, CRH mRNA, and eGFP mRNA.

Measurement of plasma osmolality and sodium. Plasma concentrations of sodium (plasma $\left[\mathrm{Na}^{+}\right]$) were measured with an automatic analyzer (Hitachi 710; Hitachi). Plasma osmolality (15 $\mu$ l plasma samples) was measured using a microsample osmometer (model 110; Fiske Associates).

RIA for plasma AVP. Plasma concentrations of AVP were determined by RIA with specific anti-AVP antisera as described previously (Onaka and Yagi, 1990). Coefficients of interassay and intraassay variations were 14 and $6 \%$. The minimum quantity detected was $0.5 \mathrm{pg} / \mathrm{ml}$.

In situ hybridization histochemistry. In situ hybridization histochemistry was performed on frozen $12-\mu \mathrm{m}$-thick coronal brain sections cut on a cryostat at $-20^{\circ} \mathrm{C}$, thawed, and mounted onto gelatin/chrome alumcoated slides. The location of the SON and the PVN was determined according to coordinates given by the atlas of Paxinos and Watson (1982). The sections including the SON matched plate 24 in the atlas. The sections including the PVN matched plate 25 in the atlas. The localization of sections from each rat was checked by microscopic observation. Two sections containing the SON and the PVN were used from each rat to measure the density of autoradiography. In situ hybridization procedures were followed as described previously (Ueta et al., 1995). Briefly, hybridization was done at $37^{\circ} \mathrm{C}$ overnight in a $45 \mu \mathrm{l}$ buffer solution consisting of $50 \%$ formamide and $4 \times$ SSC $(1 \times$ SSC: $150 \mathrm{~mm} \mathrm{NaCl}, 15 \mathrm{~mm}$ sodium citrate), which contained $500 \mu \mathrm{g} / \mathrm{ml}$ sheared salmon sperm DNA (Sigma-Aldrich), $250 \mu \mathrm{g} / \mathrm{ml}$ baker's yeast total RNA (Roche Molecular Biochemicals), $1 \times$ Denhardt's solution, and $10 \%$ dextran sulfate with molecular weight of 500,000 (Sigma-Aldrich). The hybridization was done under a Nescofilm coverslip (Bando Chemical IMD). ${ }^{35}$ S-3' -endlabeled deoxyoligonucleotides complementary to transcripts coding for AVP hnRNA (5'-GCA CTG TCA GCA GCC CTG AAC GGA CCA CAG TGG TAC-3'), c-fos mRNA (5'-CAG CGG GAG GAT GAC GCC TCG TAG TCC GCG TTG AAA CCC GAG AAC ATC-3'), CRH mRNA (5' CAG TTT CCT GTT GCT GTG AGC TTG CTG AGC TAA CTG CTC TGC CCT GGC-3'), and eGFP mRNA (5' -CGG CCA TGA TAT AGA CGT TGT GGC TGT TGT AGT TGT ACT CC-3') were used as specific probes. The specificity of the probes has been described previously (Harbuz et al., 1993; Nomura et al., 1999; Ueta et al., 2005). Total counts of $6 \times 10^{5} \mathrm{cpm} /$ slide were used. Hybridized sections containing the PVN were exposed to autoradiography film (Hyperfilm; GE Healthcare) for $7 \mathrm{~d}$. The autoradiographic images were quantified using an MCID imaging analyzer (Imaging Research). The images were captured by a chargecoupled device camera (Dage-MTI) at $40 \times$ magnifications. The mean absorbance of the autoradiographs was measured and compared with simultaneously exposed ${ }^{14} \mathrm{C}$ microscale samples (GE Healthcare). The standard curve was fitted by the absorbance of the ${ }^{14} \mathrm{C}$ microscale on the same film. To quantify the AVP hnRNA, c-fos mRNA, and eGFP mRNA levels in the magnocellular and parvocellular division of the PVN separately, areas expressing CRH mRNA in the adjacent section were delineated, and the counts of those areas were overlaid on the digitized image 
of AVP hnRNA, c-fos mRNA, and eGFP mRNA using the MCID imaging analyzer as described previously (Itoi et al., 1999) and shown in Figure 1.

Fluorescence microscopy. AVP-eGFP rats were divided into three groups (untreated, saline subcutaneous, and formalin subcutaneous; $n=6$ in each group) and treated with the method as described above. Six hours after the injection, the rats were deeply anesthetized by intraperitoneal administration of sodium pentobarbital $(50 \mathrm{mg} / \mathrm{kg})$. They were perfused transcardially with $0.1 \mathrm{M}$ phosphate buffer (PB), pH 7.4, containing heparin (1000 U/L) followed by $4 \%$ paraformaldehyde in $0.1 \mathrm{M} \mathrm{PB}$. The brains and pituitaries were removed and then divided into three blocks that included the hypothalamus. The blocks were postfixed with $4 \%$ paraformaldehyde in $0.1 \mathrm{M} \mathrm{PB}$ for $48 \mathrm{~h}$ at $4^{\circ} \mathrm{C}$. The tissues were then cryoprotected in $20 \%$ sucrose in $0.1 \mathrm{M} \mathrm{PB}$ for $48 \mathrm{~h}$ at $4^{\circ} \mathrm{C}$. Fixed brains were cut at $30 \mu \mathrm{m}$ with a microtome (Komatsu Electronics). The sections were rinsed twice with $0.1 \mathrm{M}$ PB and spread on the glass slides. The sections containing the SON, the PVN, the ME, and the PP were observed through a fluorescence microscope (ECLIPSE E 600; Nikon) with a GFP filter (Nikon) to investigate AVP-eGFP expression. The eGFP fluorescence-positive cells in the SON and the magnocellular and parvocellular divisions of the PVN were counted separately. The images were captured with a digital camera (DS-L2, DS-Fil; Nikon).

Statistical analysis. All data are given as mean \pm SEM calculated from the results of the in situ hybridization histochemistry. Each group within an experiment was compared with the control group. The data were analyzed using a one-way factorial ANOVA followed by a Bonferroni correction for multiple comparisons. Statistical significance was defined as $p<0.05$.

\section{Results}

Effects of formalin injection on plasma osmolality, $\left[\mathrm{Na}^{+}\right]$, and AVP

Plasma osmolalily and $\left[\mathrm{Na}^{+}\right]$did not change significantly between untreated and saline- or formalin-injected rats, and did not change with the passage of time over a 6 h time course (Fig. $2 A, B$ ). Plasma AVP was markedly but transiently increased $15 \mathrm{~min}$ after injection of formalin compared with untreated or saline-injected rats, with levels decreasing to those of controls after 2 and $6 \mathrm{~h}$ (Fig. 2C).

\section{Effects of formalin injection on AVP hnRNA in the PVN}

In situ hybridization histochemistry revealed that AVP hnRNA levels in the SON (Fig. 3A), the whole PVN (Fig. 3B), the magnocellular division of the PVN (Fig. 3C), and the parvocellular division of the PVN (Fig. 3D) did not change in saline-injected rats. However, the levels of AVP hnRNA were markedly increased in the whole PVN and in the parvocellular division $15 \mathrm{~min}$ and $2 \mathrm{~h}$ after formalin injection. However, the levels of the AVP hnRNA signifi- cantly increased in the SON, which includes magnocellular neurons alone, and the magnocellular division of the PVN 2 and $6 \mathrm{~h}$ after the formalin injection. The images of emulsion-dipped sections hybridized to a ${ }^{35}$ S-labeled oligodeoxynucleotide probe for AVP hnRNA in the PVN show that AVP hnRNA levels did not change in salineinjected rats but were increased in parvocellular division of the PVN at $15 \mathrm{~min}$ and $2 \mathrm{~h}$ after the formalin administration and increased as well in magnocellular division of the PVN at 2 and $6 \mathrm{~h}$ after the formalin administration (Fig. 3E). 
A

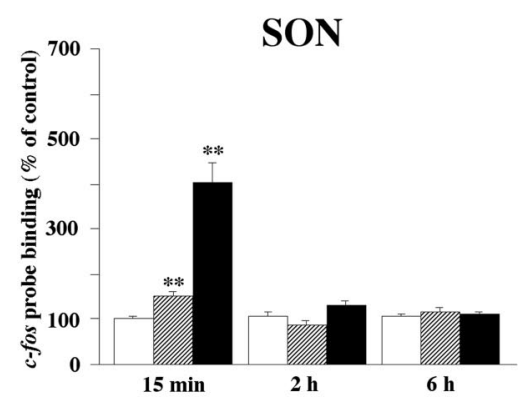

C magnocellular PVN

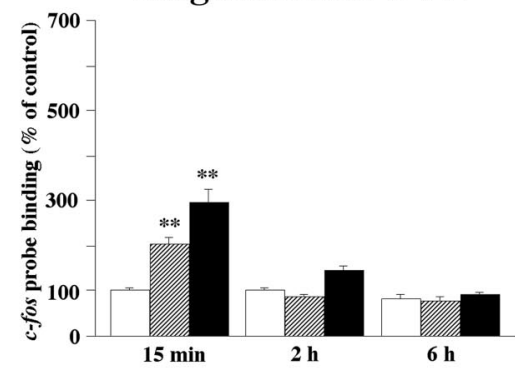

$E$
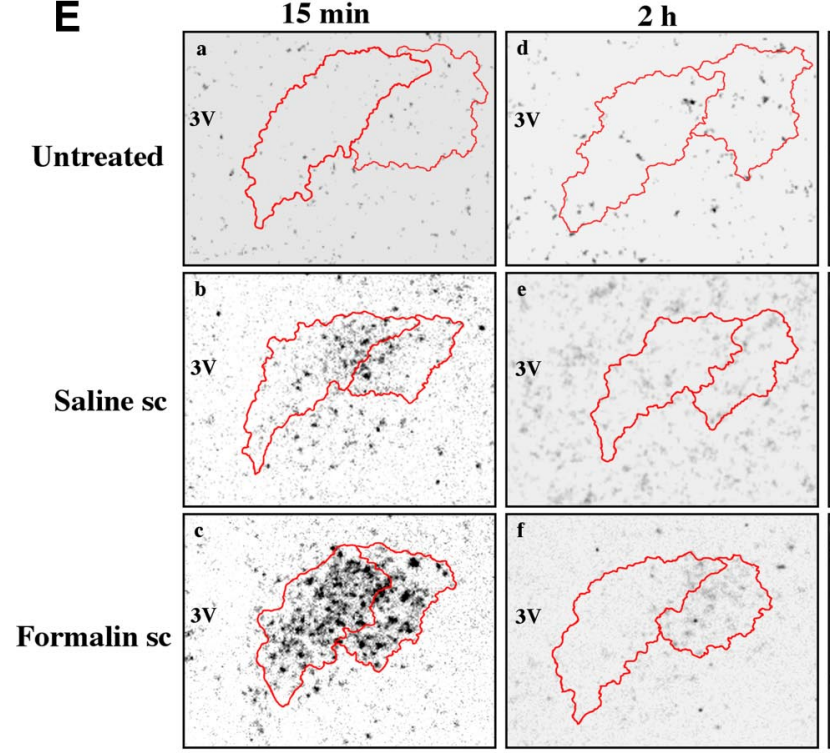

B

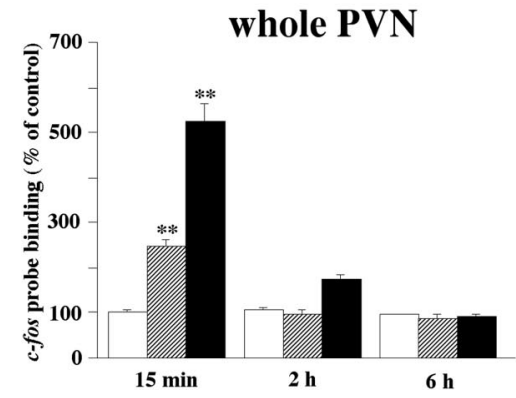

\section{D}

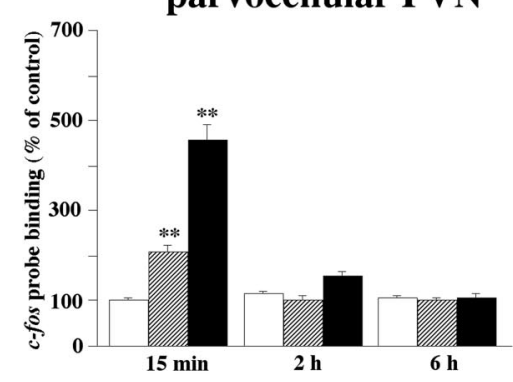

$6 \mathrm{~h}$
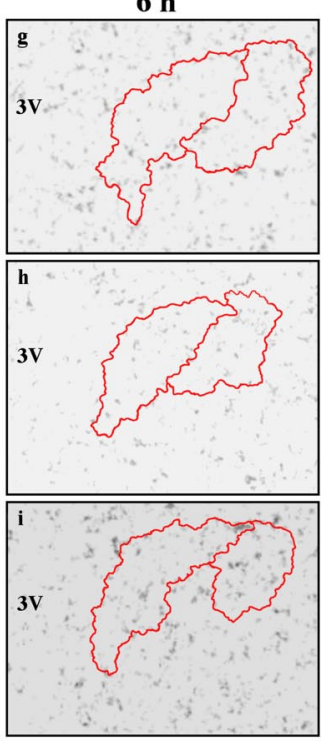

Figure 4. In situ hybridization histochemistry for detecting the c-fos mRNA levels in the SON $(\boldsymbol{A})$, the whole PVN (B), magnocellular division of the PVN $(\boldsymbol{C})$, and parvocellular division of the PVN $(\boldsymbol{D})$ in untreated rats, saline subcutaneously injected rats, and formalin subcutaneously injected rats. Points, Mean $(n=6)$; error bars,SEM. ${ }^{* *} p<0.01$ compared with each control. The micrographs of emulsiondipped sections hybridized to a ${ }^{35}$ S-labeled oligodeoxynucleotide probe complementary to mRNA for c-fos in untreated rats ( $\left.E \boldsymbol{E a}, \mathbf{E d}, \mathbf{E g}\right)$, saline subcutaneously injected rats ( $E \boldsymbol{E}, \boldsymbol{E e}, \boldsymbol{E h})$, and formalin subcutaneously injected rats (Ec, Ef, Ei). Sections were obtained at $15 \mathrm{~min}$ $(E \boldsymbol{a}-\mathbf{E c}), 2 \mathrm{~h}(\boldsymbol{E d}-\mathbf{E f})$, and $6 \mathrm{~h}(\boldsymbol{E g}-\boldsymbol{E} \boldsymbol{E})$ after injection. Scale bar, $100 \mu \mathrm{m}$. 3V, Third ventricle.

Effects of formalin injection on c-fos mRNA in the PVN The levels of c-fos mRNA in the SON (Fig. 4A), the whole PVN (Fig. $4 B$ ), the magnocellular division of the PVN (Fig. 4C), and parvocellular division of the PVN (Fig. 4D) were markedly increased at 15 min after both saline or formalin injection. Levels of c-fos mRNA had returned to normal $2 \mathrm{~h}$ after the injection. In all cases, the extent of c-fos mRNA induction by saline was much lower than that induced by formalin. The images of emulsion-dipped sections hybridized to a ${ }^{35}$ S-labeled oligodeoxynucleotide probe for c-fos mRNA in the PVN show that transcript levels increased mainly in parvocellular division of the PVN at 15 min after saline and formalin injection. However, the extent of increase was much greater in formalin-injected rats compared with saline-injected rats (Fig. $4 E$ ).

\section{Effects of formalin injection on CRH mRNA in the PVN}

The levels of CRH mRNA in the PVN did not change in saline-injected rats but were increased at $2 \mathrm{~h}$ after formalin injection, returning to control levels by $6 \mathrm{~h}$ (Fig. $5 A$ ). The images of emulsion-dipped sections hybridized to a ${ }^{35}$ S-labeled oligodeoxynucleotide probe for $\mathrm{CRH}$ mRNA in the PVN show that transcript levels were increased in the PVN at $2 \mathrm{~h}$ after formalin injection (Fig. 5B).

\section{Effects of formalin injection on eGFP mRNA in the PVN}

In situ hybridization histochemistry revealed that eGFP mRNA levels in the SON (Fig. 6A), the whole PVN (Fig. 6B), and in the magnocellular division of the PVN (Fig. 6C) and the parvocellular division of the PVN (Fig. 6D) did not change in saline-injected rats. However, a marked increase was observed in these regions 2 and $6 \mathrm{~h}$ after formalin injection. Although the levels of eGFP mRNA in parvocellular division of the PVN decreased $6 \mathrm{~h}$ after the formalin injection compared with $2 \mathrm{~h}$, they were still high compared with untreated rats. The images of emulsion-dipped sections hybridized to a ${ }^{35} \mathrm{~S}$-labeled oligodeoxynucleotide probe for eGFP mRNA in the PVN revealed that transgene transcript levels did not change in saline-injected rats but were increased both in magnocellular and parvocellular division of the PVN at 2 and $6 \mathrm{~h}$ after the formalin injection (Fig. $6 E$ ).

The changes of eGFP fluorescence in the PVN, the ME, and the PP

The eGFP fluorescence-positive cell counts did not change in saline-injected rats. However, a marked increase was observed in the SON (Fig. 7A), the whole PVN (Fig. $7 B$ ), the magnocellular division of the PVN (Fig. 7C), and the parvocellular division of the PVN (Fig. 7D) after formalin injection. The images of eGFP fluorescence revealed that formalin injection elicited a remarkable increase of fluorescence in the SON, the magnocellular and parvocellular divisions of the PVN, the internal and the external layers of the ME, and the PP (Fig. 7E).

\section{Discussion}

The present study demonstrates the effects of acute nociceptive stress elicited by formalin injection into the paw on the expression of the AVP-eGFP fusion gene in the hypothalamus of trans- 
genic rats. Plasma AVP was promptly and remarkedly increased at $15 \mathrm{~min}$ after the injection of formalin, without affecting plasma osmolality or sodium concentrations. Plasma AVP levels had returned to normal by 2 and $6 \mathrm{~h}$ after formalin injection. It is known that nociceptive stimulation can facilitate AVP release into the circulation, and pain perception processes are altered by a variety of peptides (Luttinger et al., 1984). The neurohypophysial hormones AVP and oxytocin have been shown to modify the nociception threshold induced by noxious heat stimuli, such as tail flick test or hot-plate test (Luttinger et al., 1984), and the administration of AVP antisera to the cerebral ventricle results in a small reduction in tail flick latency (Bodnar, 1986). When AVP was injected into the central nucleus of the amygdala, with subsequent monitoring of the nociceptive jaw opening reflex in freely moving rats, AVP showed an analgesic effect in diagnostic electromyograms that was inhibited by a $\mathrm{V}_{1}$, but not a $\mathrm{V}_{2}$, receptor antagonist (Ahn et al., 2001). In addition to the capacity of administered AVP to show antinociception, studies on nociceptive conditions in Brattleboro rats, which are naturally deficient in AVP, are informative concerning the role of AVP in pain sensitivity. Brattleboro rats have a hyperanalgesic state in flinch-jump threshold test and impaired stress analgesia (Bodnar et al., 1982). It could be inferred from these observations that AVP plays a role as an endogenous analgesic substance.

It is well known that AVP is secreted under stressful conditions, and several studies have also reported that AVP-secreting stimulation also caused the secretion of opioid peptides. In the PP, in which AVP and oxytocin neurons terminate, the hypophysial nerve terminals contain enkephalin peptides together with AVP or oxytocin in rat pituitary (Martin and Voigt, 1981). Dynorphin immunoreactivity was also localized in AVP and oxytocin in magnocellular neurons (Watson et al., 1982) and dynorphin is copackaged in AVP neurosecretory vesicles that are exocytosed from magnocellular neurosecretory cell dendrites and terminals (Brown and Bourque, 2004). These reports suggested that AVP and opioid peptides could be secreted from the PP and in the CNS, hence modifying the nociceptive perception.

Formalin-injected rats show two phases of nociceptive behavior, which seem to involve two distinctly different stimuli (Dubuisson and Dennis, 1977; Rosland, 1991). The first phase starts immediately after injection and lasts for $\sim 3-5 \mathrm{~min}$. It is probably attributable to direct chemical stimulation of nociceptors (Dubuisson and Dennis, 1977), and formalin predominantly evokes activity in Ad and C fibers (Heapy et al., 1987). Subsequently, there is a period of $10-15 \mathrm{~min}$ when the animals display very little behavior suggestive of nociception. The second phase starts 15-20 min after formalin injection and lasts for 20-40 min. The second phase of $\mathrm{A} \partial$ and $\mathrm{C}$ fibers activation is not uniform
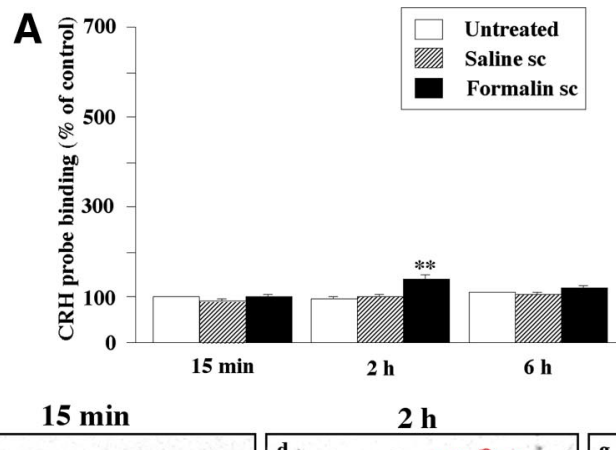

2 h

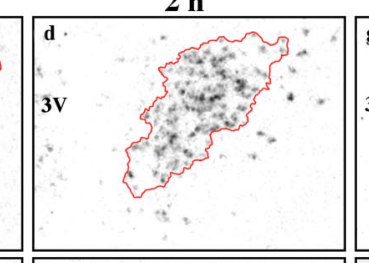

$6 \mathrm{~h}$
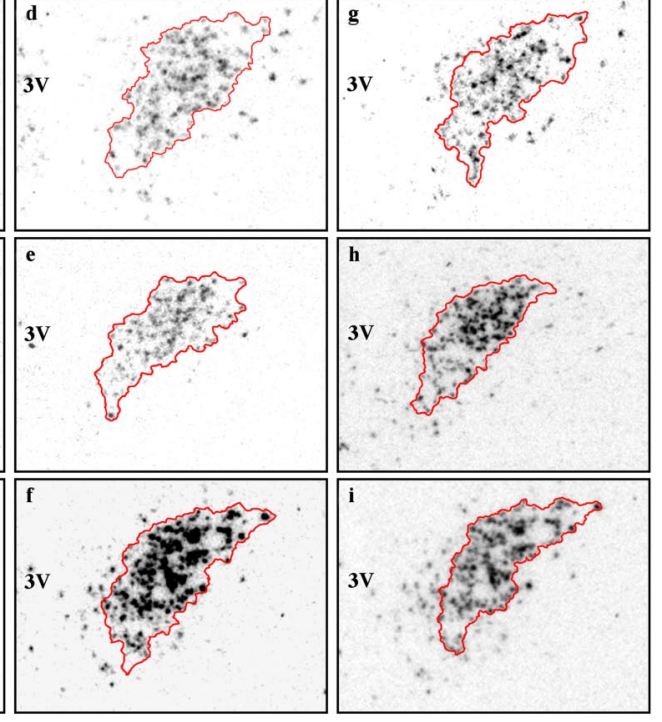

Figure 5. In situ hybridization histochemistry for detecting the CRH mRNA levels in the PVN in untreated rats, saline subcutato mRNA for $C R H$ in untreated rats $(\boldsymbol{B} \boldsymbol{a}, \boldsymbol{B d}, \boldsymbol{B} \boldsymbol{g})$, saline subcutaneously injected rats $(\boldsymbol{B} \boldsymbol{b}, \boldsymbol{B} \boldsymbol{e}, \boldsymbol{B} \boldsymbol{h})$, and formalin subcutaneously injected rats $(\boldsymbol{B C}, \boldsymbol{B f}, \boldsymbol{B i})$. Sections were obtained at $15 \mathrm{~min}(\boldsymbol{B a}-\boldsymbol{B C}), 2 \mathrm{~h}(\boldsymbol{B d}-\boldsymbol{B f})$, and $6 \mathrm{~h}(\boldsymbol{B g}-\boldsymbol{B i})$ after injection. Scale

and their activity reached less than those observed in the first phase, although the pain intensity and behavior does not change (Puig and Sorkin, 1996). Therefore, it could be reasonable that the second phase is related to the development of inflammation and spinal cord sensitization (Abram and Yaksh, 1994).

We observed that the levels of the AVP precursor hnRNA were increased in the parvocellular division of the PVN 15 min after formalin injection. The levels of c-fos mRNA were also increased in the magnocellular and, more predominantly, in the parvocellular divisions of the PVN in saline- or formalin-injected rats at 15 min after injection. This wave of transcriptional activity may reflect the first phase of nociceptive behavior, with stressreceptive neurons in the $\mathrm{A} 2 / \mathrm{C} 2$ region of the tractus solitarius (NTS) relaying sensory information and activating the parvocellular division of the PVN (Cunningham and Sawchenko, 1988). In addition, the increased levels of c-fos mRNA in saline-injected rats indicate that noxious stimulation with saline injection also evoke temporary activation of the magnocellular and parvocellular divisions of the PVN.

Although levels of c-fos mRNA returned to untreated levels by $2 \mathrm{~h}$ after formalin injection, increased levels of AVP hnRNA were maintained in both the magnocellular and the parvocellular divisions of the PVN $2 \mathrm{~h}$ after formalin injection. Simultaneously, the levels of CRH mRNA were also increased in formalin-, but 

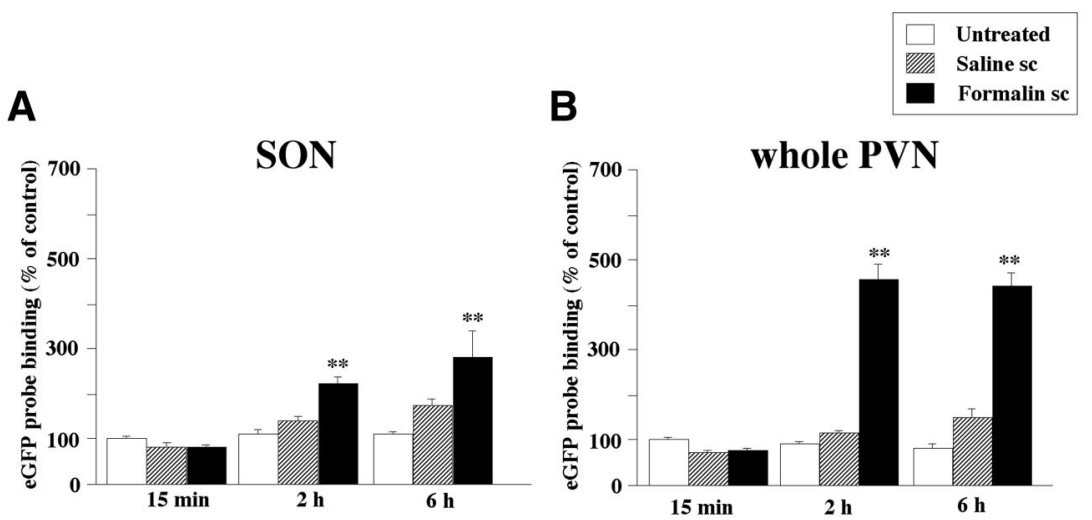

C
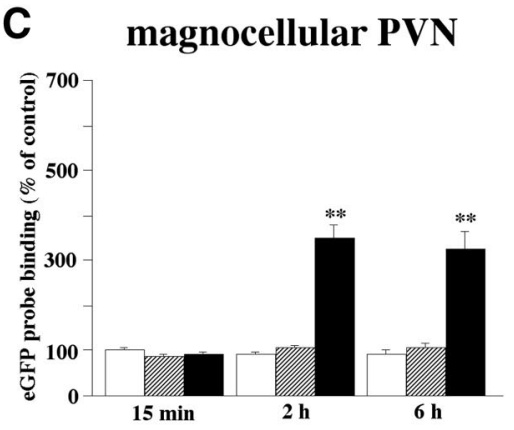

D

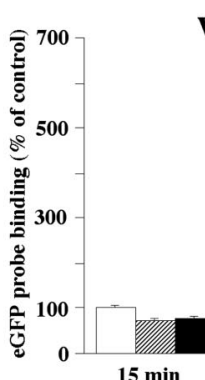

whole PVN

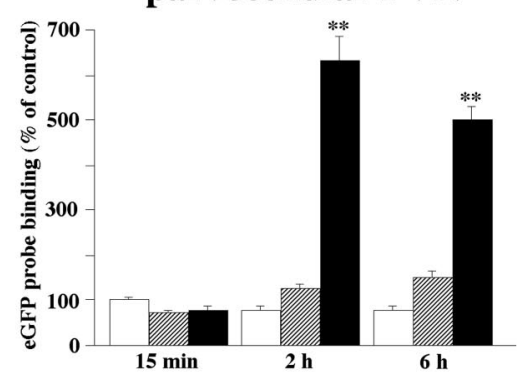

$\mathbf{E}$
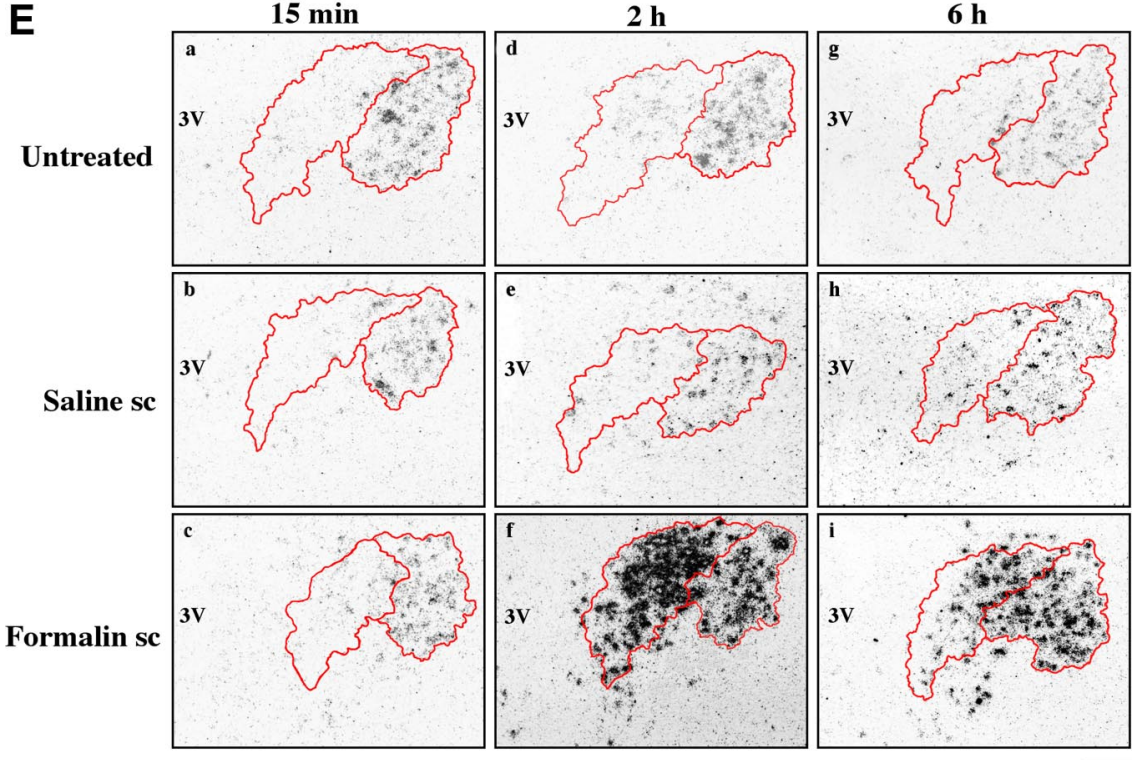

Figure 6. In situ hybridization histochemistry for detecting the arginine vasopressin-eGFP mRNA levels in the SON $(\boldsymbol{A})$, the whole PVN (B), magnocellular division of the PVN (C), and parvocellular division of the PVN (D) in untreated rats, saline subcutaneously injected rats, and formalin subcutaneously injected rats. Points, Mean $(n=6)$; error bars, SEM. ${ }^{* *} p<0.01$ compared with each control. The micrographs of emulsion-dipped sections hybridized to a ${ }^{35}$ S-labeled oligodeoxynucleotide probe complementary to mRNA for eGFP in the PVN in untreated rats $(\boldsymbol{E} \boldsymbol{a}, \boldsymbol{E d}, \boldsymbol{E g})$, saline subcutaneously injected rats $(\boldsymbol{E} \boldsymbol{b}, \boldsymbol{E e}, \boldsymbol{E} \boldsymbol{h})$, and formalin subcutaneously injected rats (Ec, Ef, Ei). Sections were obtained at $15 \mathrm{~min}(\boldsymbol{E} \boldsymbol{a}-\mathbf{E c}), 2 \mathrm{~h}(\boldsymbol{E d}-\mathbf{E f})$, and $6 \mathrm{~h}(\boldsymbol{E g}-\boldsymbol{E F})$ after injection. Scale bar, $100 \mu \mathrm{m}$. 3V, Third ventricle.

not saline-injected rats at $2 \mathrm{~h}$. The second phase of nociceptive behavior has been associated with development of peripheral inflammation. There is a discrepancy in time between the peak of the formalin-induced edema, which occurs $>4 \mathrm{~h}$ after injection in rats (Brown et al., 1968), and the second phase of nociceptive behavior, which is exhibited from 15 to $60 \mathrm{~min}$. This may reflect that firing in primary afferents subsides after $30-60 \mathrm{~min}$ because of toxic effects of formalin on the peripheral nerve fibers, even though the inflammation still evolves in the peripheral tissue.
Shibata et al. (1989) have suggested an association between second phase and peripheral release of bradykinin acting at $\mathrm{B}_{2}$ receptors and have also implicated peripheral release of histamine and serotonin in the inflammatory component. It is possible that those inflammatory mediators stimulate AVP neurons in the parvocellular division of the PVN, correlating with activation of $\mathrm{CRH}$ neurons and the HPA axis in the second phase.

The levels of transgene-encoded eGFP mRNA responded robustly to formalin injection. Indeed, the response was greatly exaggerated compared with that of the endogenous AVP hnRNA in the PVN (fourfold to sixfold induction compared with only twofold). This exaggerated response of AVP-eGFP transgene to formalin injection is very similar to that of the 5-VCAT-3 transgene to osmotic stimulation (Waller et al., 1996), and it may be a transcriptional or a posttranscriptional effect. One possibility could be that the eGFP mRNA may have a shorter half-life than its wildtype counterpart, resulting in much lower steady-state levels under basal conditions, or that the increase in eGFP mRNA could be the result of decreased eGFP mRNA degradation. We have previously shown that AVP-eGFP transgenic rats showed exaggerated increases in eGFP expression in magnocellular neurons in salt-loaded rats (Fujio et al., 2006) and in both magnocellular and parvocellular neurons in adjuvant-induced arthritic rats (Suzuki et al., 2009). Thus, it seems that changes in eGFP expression are a more sensitive indicator of changes in specific neuronal activity, readily revealing evident increases that are undetectable in wild-type rats.

Monitoring of eGFP fluorescence also allowed us to readily monitor the fate of the tagged AVP-fusion protein. As a consequence of formalin injection, eGFP fluorescence, encoded by the AVP-eGFP transgene, is apparently increased in the SON and both parvocellular and magnocellular divisions of the PVN. Increased fluorescence in the external layer of the ME reflects axonal flow from the cell bodies in the parvocellular division of the PVN to axon terminals located adjacent to the portal vein (Aguilera and RabadanDiehl, 2000). Fluorescence in the internal layer of the ME was also increased, reflecting increased axonal flow from the cell bodies in the SON and the magnocellular division of the PVN to axon terminals in the PP (Vandesande and Dierickx, 1975), resulting in increased fluorescence in the PP of formalin-injected rats.

In conclusion, the present study demonstrates that formalininduced nociceptive stimulation causes a rapid but transient elevation of plasma AVP levels; by $2 \mathrm{~h}$ plasma AVP levels had returned to normal. This correlated closely with a transient up- 
A

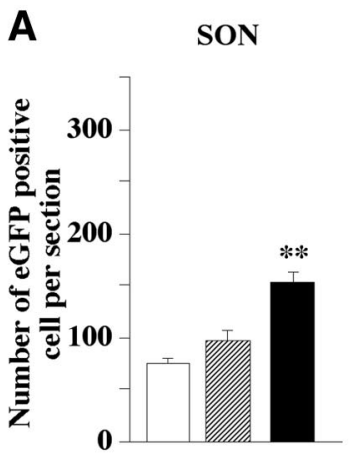

$\mathbf{E}$
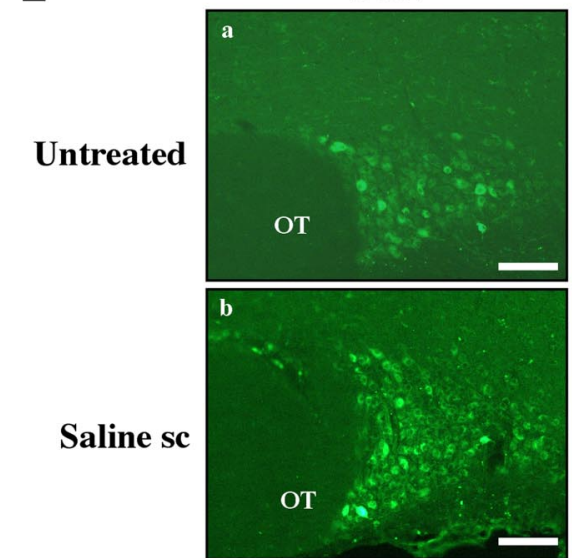

Formalin sc

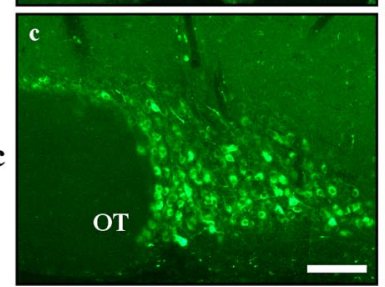

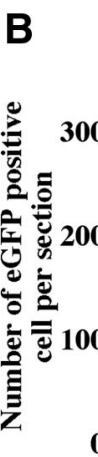

Whole PVN
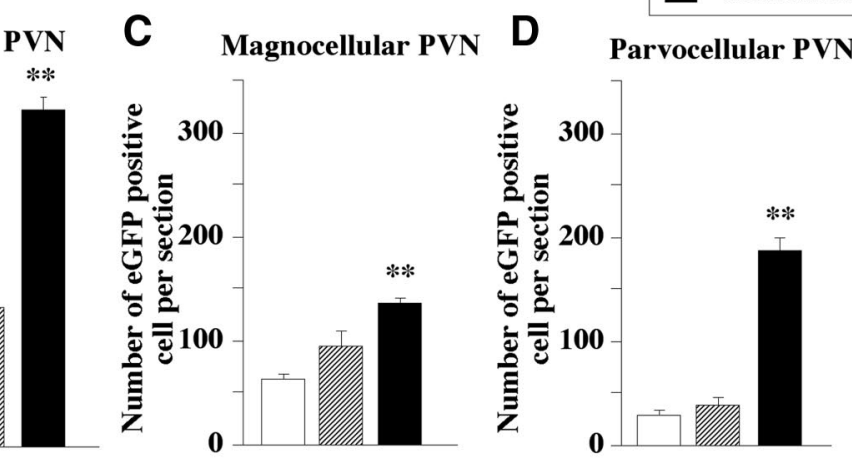

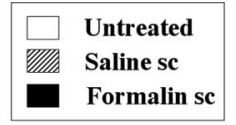

PVN
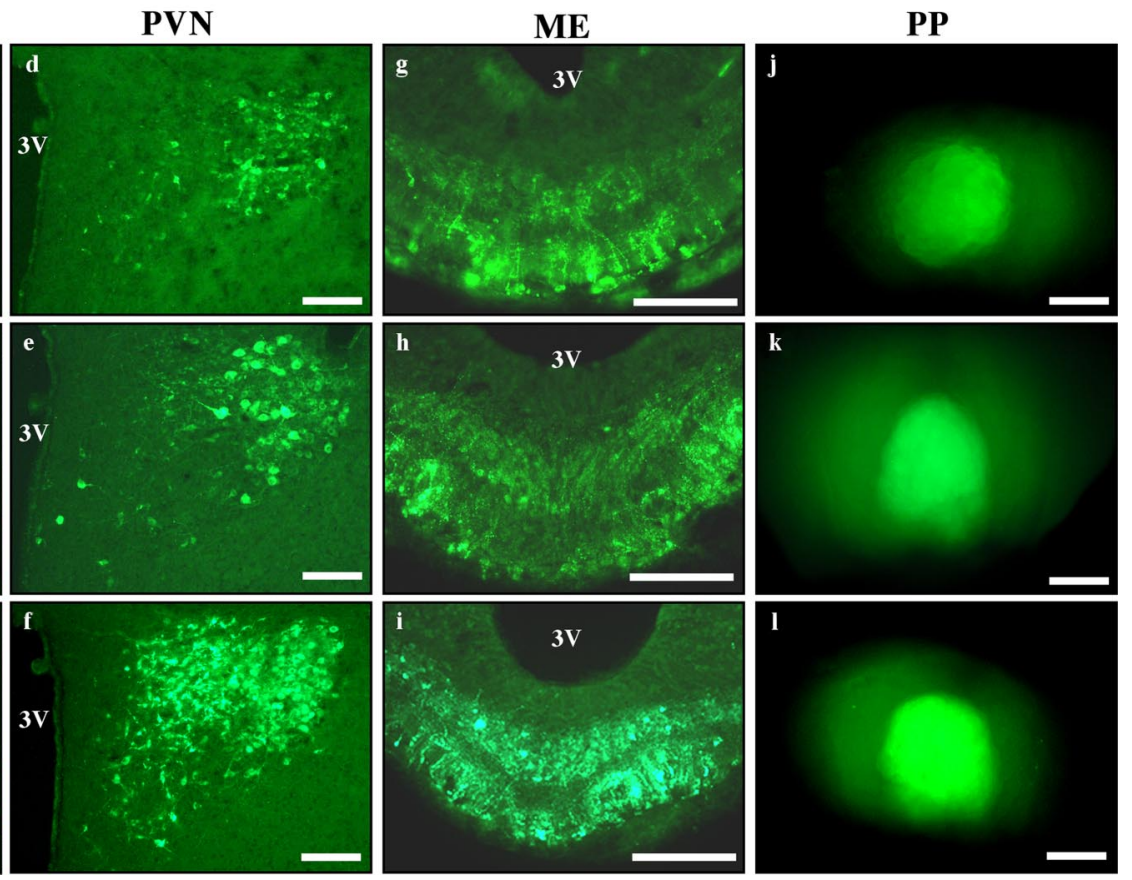

Figure 7. The arginine vasopressin-eGFP fluorescent-positive cell counts in the SON $(\boldsymbol{A})$, the whole PVN $(\boldsymbol{B})$, the magnocellular division of the PVN $(\boldsymbol{C})$, and the parvocellular division of the PVN (D) in untreated rats, saline subcutaneously injected rats, and formalin subcutaneously injected rats. Points, Mean $(n=6)$; error bars, SEM. ${ }^{* *} p<0.01$ compared with each control. The eGFP

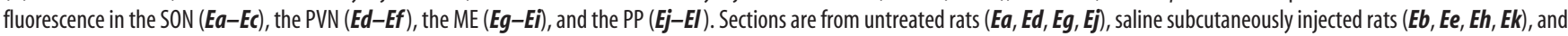
formalin subcutaneously injected rats (Ec, Ef, Ei, EI). Scale bars: Ea-Ef, $100 \mu \mathrm{m} ; \boldsymbol{E g}-\mathbf{E i}, 50 \mu \mathrm{m} ; \boldsymbol{E j}-\mathbf{E I}, 1 \mathrm{~mm}$. 0T, 0ptic track; 3V, third ventricle.

regulation of the expression of c-fos in the parvocellular and magnocellular divisions of the PVN. AVP hnRNA was also rapidly upregulated, but unlike c-fos expression, this was maintained for a much longer period. The upregulation of the AVP gene in the parvocellular division of the PVN may activate the HPA axis, correlating with induction of the $\mathrm{CRH}$ gene in the second phase of the nociceptive behavioral response. Moreover, because AVPeGFP transgenic rats can demonstrate AVP expression in the form of green fluorescence, we can detect these changes in AVP expression more easily than by using other approaches, such as immunohistochemistry. AVP-eGFP transgenic rats allow monitoring of the amplified AVP gene activation compared with wildtype rats, since the response of the eGFP gene was more sensitive and exaggerated compared with that of AVP hnRNA. These rats can thus be used to investigate the dynamics of the synthesis and secretion of AVP in living neurons/terminals and the resolution of the physiological role of AVP neurons by monitoring their biological effects.

\section{References}

Abbott FV, Melzack R, Samuel C (1982a) Morphine analgesia in tail-flick and formalin pain tests is mediated by different neural systems. Exp Neurol 75:644-651.

Abbott FV, Melzack R, Leber BF (1982b) Morphine analgesia and tolerance in the tail-flick and formalin tests: dose-response relationships. Pharmacol Biochem Behav 17:1213-1219.

Abram SE, Yaksh TL (1994) Systemic lidocaine blocks nerve injury-induced hyperalgesia and nociceptor-driven spinal sensitization in the rat. Anesthesiology 80:383-391; discussion 325A.

Aguilera G, Rabadan-Diehl C (2000) Regulation of vasopressin V1b receptors in the anterior pituitary gland of the rat. Exp Physiol 85:19S-26S.

Ahn DK, Kim KH, Ju JS, Kwon S, Park JS (2001) Microinjection of arginine vasopressin into the central nucleus of amygdala suppressed nociceptive jaw opening reflex in freely moving rats. Brain Res Bull 55:117-121.

Aloisi AM, Albonetti ME, Muscettola M, Facchinetti F, Tanganelli C, Carli G (1995) Effects of formalin-induced pain on ACTH, beta-endorphin, corticosterone and interleukin- 6 plasma levels in rats. Neuroendocrinology 62:13-18.

Aloisi AM, Albonetti ME, Carli G (1996) Formalin-induced changes in ad- 
renocorticotropic hormone and corticosterone plasma levels and hippocampal choline acetyltransferase activity in male and female rats. Neuroscience 74:1019-1024.

Antoni FA (1993) Vasopressinergic control of pituitary adrenocorticotropin secretion comes of age. Front Neuroendocrinol 14:76-122.

Bodnar RJ (1986) Neuropharmacological and neuroendocrine substrates of stress-induced analgesia. Ann N Y Acad Sci 467:345-360.

Bodnar RJ, Wallace MM, Kordower JH, Nilaver G, Cort J, Zimmerman EA (1982) Modulation of nociceptive thresholds by vasopressin in the Brattleboro and normal rat. Ann N Y Acad Sci 394:735-739.

Brown CH, Bourque CW (2004) Autocrine feedback inhibition of plateau potentials terminates phasic bursts in magnocellular neurosecretory cells of the rat supraoptic nucleus. J Physiol 557:949-960.

Brown JH, Kissel JW, Lish PM (1968) Studies on the acute inflammatory response. I. Involvement of the central nervous system in certain models of inflammation. J Pharmacol Exp Ther 160:231-242.

Culman J, Ritter S, Ohlendorf C, Haass M, Maser-Gluth C, Spitznagel H, Unger T (1997) A new formalin test allowing simultaneous evaluation of cardiovascular and nociceptive responses. Can J Physiol Pharmacol 75:1203-1211.

Cunningham ET Jr, Sawchenko PE (1988) Anatomical specificity of noradrenergic inputs to the paraventricular and supraoptic nuclei of the rat hypothalamus. J Comp Neurol 274:60-76.

Dennis SG, Melzack R (1980) Pain modulation by 5-hydroxytryptaminergic agents and morphine as measured by three pain tests. Exp Neurol 69:260-270.

Dubuisson D, Dennis SG (1977) The formalin test: a quantitative study of the analgesic effects of morphine, meperidine, and brain stem stimulation in rats and cats. Pain 4:161-174.

Fujio T, Fujihara H, Shibata M, Yamada S, Onaka T, Tanaka K, Morita H, Dayanithi G, Kawata M, Murphy D, Ueta Y (2006) Exaggerated response of arginine vasopressin-enhanced green fluorescent protein fusion gene to salt loading without disturbance of body fluid homeostasis in rats. J Neuroendocrinol 18:776-785.

Harbuz MS, Lightman SL (1992) Stress and the hypothalamo-pituitaryadrenal axis: acute, chronic and immunological activation. J Endocrinol 134:327-339.

Harbuz MS, Chalmers J, De Souza L, Lightman SL (1993) Stress-induced activation of CRF and c-fos mRNAs in the paraventricular nucleus are not affected by serotonin depletion. Brain Res 609:167-173.

Heapy CG, Jamieson A, Russell NJW (1987) Afferent C-fibre and A-delta activity in models of inflammation. Br J Pharmacol 90:164.

Itoi K, Helmreich DL, Lopez-Figueroa MO, Watson SJ (1999) Differential regulation of corticotropin-releasing hormone and vasopressin gene transcription in the hypothalamus by norepinephrine. J Neurosci 19:5464-5472.

Kendler KS, Weitzman RE, Fisher DA (1978) The effect of pain on plasma arginine vasopressin concentrations in man. Clin Endocrinol (Oxf) 8:89-94.

Kurose T, Ueta Y, Nomura M, Yamaguchi K, Nagata S (2001) Nociceptive stimulation increases NO synthase mRNA and vasopressin heteronuclearRNA in the rat paraventricular nucleus. Auton Neurosci 88:52-60.

Luttinger D, Hernandez DE, Nemeroff CB, Prange AJ Jr (1984) Peptides and nociception. Int Rev Neurobiol 25:185-241.

Martin R, Voigt KH (1981) Enkephalins co-exist with oxytocin and vasopressin in nerve terminals of rat neurohypophysis. Nature 289:502-504.

Nomura M, Ueta Y, Serino R, Yamamoto Y, Shibuya I, Yamashita H (1999)
Effects of centrally administered pituitary adenylate cyclase-activating polypeptide on c-fos gene expression and heteronuclear RNA for vasopressin in rat paraventricular and supraoptic nuclei. Neuroendocrinology 69:167-180.

Onaka T, Yagi K (1988) Bimodal effects of noxious stimuli on vasopressin secretion in rats. Neurosci Res 6:143-148.

Onaka T, Yagi K (1990) Differential effects of naloxone on neuroendocrine responses to fear-related emotional stress. Exp Brain Res 81:53-58.

Onaka T, Hamamura M, Yagi K (1986) Potentiation of vasopressin secretion by footshocks in rats. Jpn J Physiol 36:1253-1260.

Onaka T, Palmer JR, Yagi K (1996) A selective role of brainstem noradrenergic neurons in oxytocin release from the neurohypophysis following noxious stimuli in the rat. Neurosci Res 25:67-75.

Pacák K, Palkovits M, Kvetnanský R, Yadid G, Kopin IJ, Goldstein DS (1995) Effects of various stressors on in vivo norepinephrine release in the hypothalamic paraventricular nucleus and on the pituitary-adrenocortical axis. Ann N Y Acad Sci 771:115-130.

Paxinos G, Watson C (1982) The rat brain in stereotaxic coordinates. Sydney: Academic

Persoons JH, Moes NM, Broug-Holub E, Schornagel K, Tilders FJ, Kraal G (1997) Acute and long-term effects of stressors on pulmonary immune functions. Am J Respir Cell Mol Biol 17:203-208.

Puig S, Sorkin LS (1996) Formalin-evoked activity in identified primary afferent fibers: systemic lidocaine suppresses phase- 2 activity. Pain 64:345-355.

Rosland JH (1991) The formalin test in mice: the influence of ambient temperature. Pain 45:211-216.

Shibata M, Ohkubo T, Takahashi H, Inoki R (1989) Modified formalin test: characteristic biphasic pain response. Pain 38:347-352.

Suzuki H, Onaka T, Kasai M, Kawasaki M, Ohnishi H, Otsubo H, Saito T, Hashimoto H, Yokoyama T, Fujihara H, Dayanithi G, Murphy D, Nakamura T, Ueta Y (2009) Response of arginine vasopressin-enhanced green fluorescent protein fusion gene in the hypothalamus of adjuvantinduced arthritic rats. J Neuroendocrinol 21:183-190.

Taylor BK, Akana SF, Peterson MA, Dallman MF, Basbaum AI (1998) Pituitary-adrenocortical responses to persistent noxious stimuli in the awake rat: endogenous corticosterone does not reduce nociception in the formalin test. Endocrinology 139:2407-2413.

Ueta Y, Levy A, Chowdrey HS, Lightman SL (1995) Hypothalamic nitric oxide synthase gene expression is regulated by thyroid hormones. Endocrinology 136:4182-4187.

Ueta Y, Fujihara H, Serino R, Dayanithi G, Ozawa H, Matsuda K, Kawata M, Yamada J, Ueno S, Fukuda A, Murphy D (2005) Transgenic expression of enhanced green fluorescent protein enables direct visualization for physiological studies of vasopressin neurons and isolated nerve terminals of the rat. Endocrinology 146:406-413.

Vandesande F, Dierickx K (1975) Identification of the vasopressin producing and of the oxytocin producing neurons in the hypothalamic magnocellular neurosecretory system of the rat. Cell Tissue Res 164:153-162.

Waller S, Fairhall KM, Xu J, Robinson IC, Murphy D (1996) Neurohypophyseal and fluid homeostasis in transgenic rats expressing a tagged rat vasopressin prepropeptide in hypothalamic neurons. Endocrinology 137:5068-5077.

Watson SJ, Akil H, Fischli W, Goldstein A, Zimmerman E, Nilaver G, van wimersma Griedanus TB (1982) Dynorphin and vasopressin: common localization in magnocellular neurons. Science 216:85-87. 